\title{
Sık Karşılaşılan Kemik Mineral Yoğunluk Ölçümü (DKA: Dual X-Ray Absorbsiyometri) Hataları: Tek Merkezli, Retrospektif Kesitsel Çalışma
}

Common Bone Mineral Density Mesurement (DXA: Dual X-Ray Absorbsiometry) Mistakes: Single Center, Retrospective Cross-Sectional Study Sinan Bağçacı ${ }^{1}$ (D) İbrahim Uğurlu²

1 Fizyoterapi ve Rehabilitasyon Bölümü, Sağlık Bilimleri Yüksekokulu, KTO Karatay Üniversitesi, Karatay, Konya/Türkiye 2 Tıbbi Görüntüleme Teknikleri Programı, Sağlık Hizmetleri Meslek Yüksekokulu, Selçuk Üniversitesi, Selçuklu, Konya/Türkiye

\section{ÖzeT}

AMAÇ: Tek merkezli retrospektif ve kesitsel olarak yapılan bu çalışmanın amacı; merkezimizde yaygın yapılan DXA çekim hatalarının tanımlanması, bu sayede standardizasyon ve operatör eğitimine katkı sunmaktır.

GEREÇ VE YÖNTEM: DXA ölçümlerinde lomber ve proksimal femur ölçümleri kayıt altına alınmıştır. Ön kol ölçümü, total vücut ölçümü ve çocuklarda yapılan ölçümler çalışmaya alınmamıştır. Lomber ve kalça ölçümlerine ait DXA hataları ayrı ayrı tanımlanarak kaydedildi.

BULGULAR: 762 DXA ölçümü değerlendirildi. Değerlendirme sonucunda, 616 DXA çekiminde hatalı ölçüm tespit edildi. Bu hataların 374'ü proksimal femur ölçümünde, 242 tanesi ise lomber omurga ölçümünde tespit edildi.

SONUÇ: Tek merkezli retrospektif ve kesitsel olarak yapılan bu çalışma ile; merkezimizde yaygın olarak DXA çekim hataları yapıldığı ve bu durumun düzeltilmesi için standardizasyon, operatör eğitimi ve analiz bilgisi verilmesi gerektiği ortaya konulmuştur.

Anahtar Kelimeler: osteoporoz, teşhis, dual enerji x-ışını absorbsiyometri, teknisyen, eğitim

\section{ABSTRACT}

OBJECTIVE: The aim of this single-center retrospective and cross-sectional study was; of common DXA measurement errors in our center, thus contributing to standardization and operator training.

MATERIALS AND METHODS: DXA measurements of lumbar and proximal femur measurements were recorded. Forearm measurement, total body measurement and measurements in children were not included in the study. DXA errors of lumbar and hip measurements were identified and recorded separately.

RESULTS: 762 DXA measurements were evaluated. As a result of the evaluation, incorrect measurement was detected in 616 DXA shots. 374 of these errors were detected in proximal femur measurement and 242 of them were detected in lumbar spine measurement.

CONCLUSION: In this single-center retrospective and cross-sectional study; It turned out that DXA shooting errors are common in our center and that standardization, operator training and analysis in formation should be provided to correct this situation.

Keywords: osteoporosis, diagnosis, dual energy x-ray absorptiometry, technician, education

\section{Giriş}

Kemik mineral yoğunluk ölçümü osteoporozun ve osteoporoza bağlı kırık riskinin indirekt belirtecidir (1). Kemik mineral yoğunluk ölçümü teknikleri DXA: Dual X-Ray absorbsiyometri, kantitatif ultrason ve kantitatif bilgisayarlı tomografidir. DXA ile yapılan kemik mineral yoğunluk ölçümlerinde referans teknik olarak tüm vücut, lomber omurga, önkol ve proksimal femur çekimleri yapılmaktadır $(2,3)$.

Dünya Sağlık Örgütü (DSÖ) DXA ölçüm tekniğini kemik mineral yoğunluk ölçümü için en iyi teknik olarak belirtmektedir. DXA doğru biçimde osteoporoz tanısı yanında tedavi gören hastalarda tedaviye yanıtın monitörizasyonu ve hastalardaki kırık riskinin tahmini için oldukça değerlidir $(1,4)$. DXA ölçümünde öncelikli amaç; kemik mineral yoğunluğunun doğru biçimde ölçümü yanında referans toplumda yer alan asemptomatik bireylerin bu ölçüm ile kıyaslanmasıdır. Kemik mineral yoğunluk ölçümünde tespit edilen düşük değerler omurga ve kalçanın kırık riskini işaret etmektedir. Benzer şekilde serum kolesterol yüksekliği ile kalp hastalı̆̆ı, yüksek kan basıncı inme riskini de tahmin edilebilmektedir (1). DXA aynı

Yazışma Adresi/Address for Correspondence: İbrahim Uğurlu, MD, Fiziksel Tıp ve Rehabilitasyon Bölümü, Bor FTR EAH Niğde/Türkiye 
zamanda FDA tarafından onaylanmış tedavi ajanlarının etkinliğinin değerlendirilmesinde oldukça kullanışlıdır. DXA'nın avantajları güvenli olması, kısa çekim süresi ve kullanım kolaylığıdır. DXA ölçümü minimal radyasyon maruziyeti taşımakta ve birkaç dakika içerisinde ölçüm tamamlanmaktadır. Kemik mineral yoğunluk ölçümü için DXA ile oldukça doğru sonuçlar elde edilmektedir(3). Her ne kadar cihaz ve ölçüm yapan kişiden etkilenme olabilse de oldukça doğru sonuçlar elde edilmektedir. Operatör hataları hem uzun dönem hem de kısa dönmede ortaya çıkabilen hatalardır (5).

Hastanın pozisyonlanması ve hastada çalışılacak alanın belirlenmesi operatöre bağlı durumdur. Dünyada 5 bin üzerinde DXA çekimi için kullanılan cihaz mevcuttur (5). Bu cihazlarda çekim yapan operatörlerin eğitimi; farklı merkez ve ülkelerde gerçekleştirilmekle birlikte henüz standardize edilmemiştir. Bundan dolayı yapılan hatalı çekimlerin analizi, düzeltilmesi ile ilgili oldukça kısıtlı bilgi düzeyi bulunmaktadır $(6,7)$.

Kemik mineral yoğunluk ölçümünde yaygın karşılaşılan hataları dört kategoride ele almak mümkündür:

1) Indikatör hataları,

2) Kontrol ve kalibrasyon kalitesinin az olması,

3) Analiz ve yorumlama hataları,

4) Veri elde etme hataları (8).

Veri elde edilmesine bağı çekim hataları daha önce yapılan çalışmalarda oldukça iyi tanımlanmıştır: Hastanın uygunsuz pozisyonlanması, uygun olmayan tarama modu seçilmesi, uygun olmayan iskelet tarafı, inceleme yapılan bölgelerde sürekli artefakt olması ve doğru edinilmeyen demografik bulgular olarak sayılabilir. Daha önce Karahan ve ark. yaptığı çok merkezli çalışmada bu tür yaygın hataları oldukça güzel biçimde tanımlamıştır (9). Bizim çalışmamız ise çalıştığımız merkezde DXA ölçüm hatalarını tanımlamak ve bu hatalar ile standardizasyon ve operatör eğitimine katkı sunmayı amaçlamaktadır.

\section{GEREÇ VE YÖNTEM}

Bu çalışmada; retrospektif olarak, Aralık 2015 ile Aralık 2017 yılları arasında KTO Karatay Üniversitesi Medicana Tıp Fakültesi Hastanesinde çekilen DXA sonuçları ele alınmıştır. Çalışma için KTO Karatay Üniversitesi İnsan Araştırmaları Etik Kurulundan (Tarih:25.09.2018, Karar No:18/002) etik kurul onayı alınmıştır.
Bu çalışmada Fantom DXA ölçümleri Hologic QDR 4500 Elite sistemine sahip cihazda yapılmıştır. DXA kalite kontrol fantomu normal kemik yoğunluğuna sahip $(1,00 \mathrm{gr} / \mathrm{cm} 2) \mathrm{L} 1$ L4 vertebralardan oluşan fantom kullanılmıştır. Merkezimizde belirtilen zaman diliminde endikasyon dahilinde istenen ve çekimi yapılan DXA ölçümlerinin tamamı incelenmiştir. Bu zaman diliminde radyoloji departmanında görevli olan ekipteki teknisyenler tarafından yapılan DXA ölçümleri ele alınmıştır. Teknisyenlere çalışma öncesinde eğitim verilmemiştir. Lomber ve kalça ölçümüne ait değerler içeren DXA ölçümleri değerlendirmeye alınmıştır. Belirtilen süreler içerisinde çekilen tüm DXA ölçümleri çalışmaya dahil edilmiş, ön kol çekimi, total vücut çekimi ve çocuklar üzerinde yapılan çekimler çalışmaya alınmamıştır.

2 araştırmacı DXA çekimi hatalarının taranması konusunda çalışma öncesinde bilgilendirilmiştir.

Incelemelerin doğruluğunu değerlendirmek için; Uluslararası Klinik Dansitometre Derneği (International Society of Clinical Densitometry) tarafından ortaya atılan doğru ölçüm rehberinde yer alan standartlar temel alınarak geliştirilen aşağıdaki kriterler kullanılmıştır(8).

\section{Lomber omurga için;}

- Omurga merkezi konumda olmalı ve düzgün bir hat üzerine yerleşmeli (spinöz çıkıntılar üzerinde merkezi konumda olmalı)

- Inceleme L1 den L5'e kadar omurgayı içine almalı, aynı zamanda T12 omurgaya kaburganın yapıştığı yeri de en yukarıda görüntü içine almalı

- Görüntü alanı içerisinde iliak kreste ait küçük bir alan alt köşelerde yer almalı

- Omurganın kenarında benzer miktarda yumuşak dokuya ait görünüm olmalı

Çalışma alanı doğru bir biçimde yerleşim göstermelidir. İlgilenilen alan içerisinde yumuşak dokular eşit miktarda dağılım göstermeli, görüntü içerisinde aşırı miktarda iliak krest ve kaburgalara ait imaj yer almamalıdır. Çalışma alanı içinde vertebralar düzgün bir biçimde yerleşim göstermelidir.

Çalışma alanı içinde artefakta neden olabilecek metal gibi yabancı cisim, cerrahi klipsleri, kontrast maddeler, plastik eşyalar, mücevherler ve düğmeler olmamalıdır. 
Çalışma alanı içerisinde sonuçları değiştirebilecek laminektomi ya da spina bifida okülta gibi anatomik değişiklikler olmamalıdır.

Çalışılan alanda yanlış değerlendirmeye neden olabilecek Paget hastalı̆̆ı, ankilozan spondilit, aortik kalsifikasyon, ciddi skolyoz, ankilozan hiperosteozis ve aşırı dejenerasyon olmamalıdır.

\section{Proksimal femur için;}

Görüntü içerisinde femur başı, boynu ve yaklaşık olarak femur gövdesine ait $7,5 \mathrm{~cm}$ ya da 3 inçlik kısım bulunmalıdır. Femur şaft inceleme için kullanılan üçgenin uzun kenarına paralel olmalıdır. Büyük trokanterin dış yan kısmında yeterli yumuşak doku yer almalıdır. Kalçanın internal rotasyonu küçük trokanterin ya görünmemesi ya da çok az görünümü ile doğrulanmalıdır.

Femur başının çalışma alanı içerisinde yer alan doğru yerleşimi çekim yapılan cihazdan cihaza farklılık gösterebilmektedir. Genellikle çalışma alanı içerisinde büyük trokanter, proksimal femur boynu ve femur başı doğru biçimde yerleşim göstermelidir. Çalışılan alan içerinde çekimi etkileyebilecek kırık, kallus formasyonu ve mesane taşı olmamalıdır (Şekil 1).

Şekil 1. Lomber ve proksimal femur taramasında doğru konumlandırma. Şekil 1-A: Lomber Vertebra taramasında doğru konumlandırma. Şekil 1-B: Proksimal Femur taramasında doğru konumlandırma.
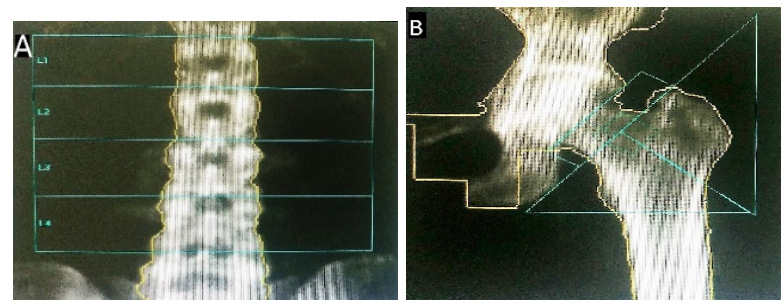

Verilerin istatistiksel analizi, bilgisayarlı yazılım programı SPSS sürüm 13 (SPSS, Inc., Chicago, IL, ABD) kullanılarak yapıldı. İstatistiksel analiz planı için bazı değişkenler; kategorik ve türetilmiş değişkenler tasarlandı. Veriler ortalama \pm standart sapma olarak verildi. Demografik ve klinik özellikler ki-kare testi (CHI-SQUARE TEST) kullanılarak karşılaştırıldı. Bağımsız örneklerin karşılaştırılmasında, iki grup için $T$ testi kullanıldı. 0.05'ten küçük "p" değeri istatistiksel olarak anlamlı kabul edilmiştir.

\section{BULGULAR}

KTO Karatay Üniversitesi Medicana Tıp Fakültesi Hastanesinden elde edilen toplam 762 DXA tarama sonucu incelendi. Çalışmada incelenen DXA ölçüm değerleri 762 hastadan iken bu hastaların 659'u kadın, 103'ü erkek hastaya ait idi. Kadın hastaların ortalama yaşı 63.2 \pm 22.1

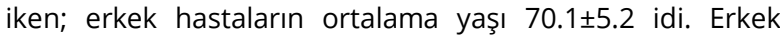
hastaların yaş ortalaması kadın hastalarınkinden istatiksel olarak anlamlı daha yüksekti $(p=0,001)$ (Tablo 1).

Tablo-1: DXA ölçümü verileri elde edilen hastaların demografik özellikleri

\begin{tabular}{|ccc|}
\hline $\begin{array}{c}\text { Cinsiyet } \\
\text { Yaş }\end{array}$ & Kadın 659 (\%86,5) & Erkek 103 (\%13,5) \\
\hline
\end{tabular}

Kriterlerimize göre lomber omurga ölçümünde $n=242$ ve \% 31,7 oranında ölçüm hatası tespit edilirken; proksimal femur ölçümlerinde yapılan değerlendirmede ise $n=374$ ve \% 49.0 oranında DXA ölçüm hatası tespit edildi. İlgilenilen bölgenin tanımlanmasındaki hatalar, lomber omurga sonuçlarında karşılaşılan en yaygın hataydı $(\% 16,2, n=124)$. Diğer hatalar arasında, yapay ve yabancı cisimlerin varlı̆̆ı, ilgilenilen bölgenin yanal hizalanması, laminektomi defektleri, Paget hastalığı, ciddi skolyoz ve dejeneratif değişiklikler vardı. İlgilenilen bölge belirlenmesinde yapılan hataların sıklığı diğer yapılan lomber DXA ölçüm hatalarından istatiksel olarak anlamlı olarak farklılık gösterdi ( $p=0,011$ ) (Tablo 2).

Tablo-2: Lomber omurga DXA ölçüm hataları

\begin{tabular}{|rcc|}
\hline Toplam & $\mathrm{n}=242(\% 31,7)$ & p değeri \\
Bölge tanımlama hatası & $124(\% 16,2)$ & ${ }^{*} 0,011$ \\
Yanal hizalama hatası & $37(\% 4,85)$ & 0,114 \\
Aşırı dejenerasyon varlığı & $28(\% 3,67)$ & 0,326 \\
Yabancı cisim varlığı & $22(\% 2,88)$ & 0,561 \\
Laminektomi defekti & $18(\% 2,36)$ & 0,716 \\
Paget hastalı̆̆ı ve ciddi skolyoz & $13(\% 1,7)$ & 0.735 \\
\hline
\end{tabular}

Proksimal femur ölçümlerinde en sık görülen diskalifiye edici hata ise kalça iç rotasyonunun yetersiz olmasıydı (\%29.3, n =224). Diğer hatalar ise ilgilenilen alanın hatalı tanımlanması, abartılı kalça abduksiyon ya da addüksiyonu, taranan alandaki yabancı cisimler, doğuştan kalça çıkı ̆̆ ve sınırlı veya dar tarama alanıydı (Şekil 2, Şekil 3). Proksimal femur ölçümlerinde yetersiz kalça iç rotasyonu hatası en sık görülmekle birlikte diğer çekim hatalarından istatiksel olarak anlamlı farklılık gösterdi $(p=0,001)$ (Tablo3). 
Şekil 2. Lomber omurga DXA ölçümlerinde yaygın hata kaynakları. Şekil 2-A/B: ROI'nin yanlış yerleştirilmesi. Şekil 2-C/D: Odak bölgesi seçimindeki hata. Şekil 2-E:Artefakt oluşturan cisim mevcut. Şekil 2-F: L1 düzeyinde implant. Şekil 2-G: Columna vertebraliste yoğun dejenerasyon mevcut. Şekil 2-H:Artefakt oluşturan cisim mevcut. Şekil 2-I: Nefrolitiyazis.

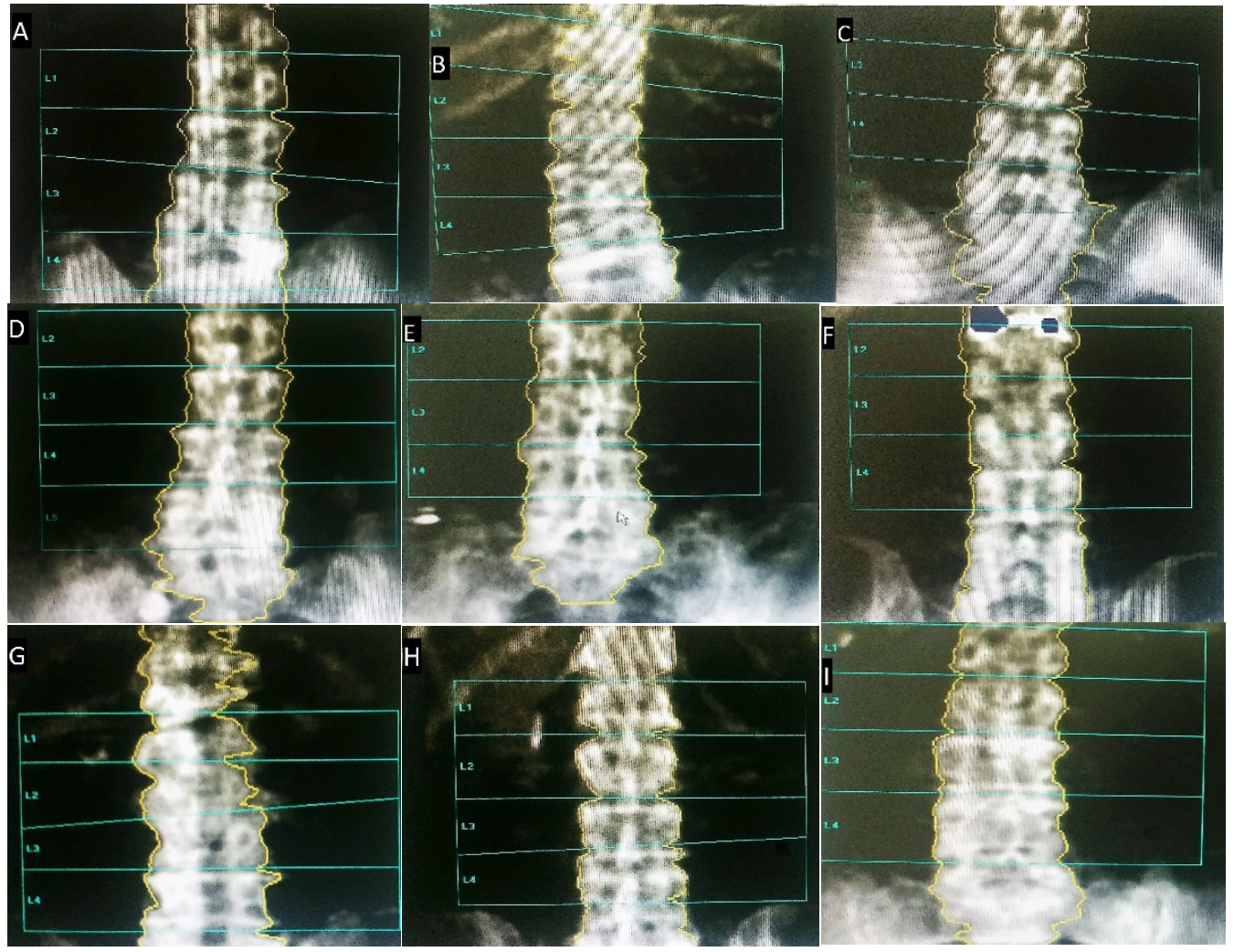

Şekil 3. Proksimal femur ölçümlerinde karşılaşılan yaygın hata kaynakları. Şekil 3-A/B: Kalçanın yetersiz iç rotasyonu. Şekil 3-C:Femur boyun bölgesinin yanlış odak noktası olarak belirlenmesi. Şekil 3-D: Kalçanın abartılı abdüksiyonu. Şekil 3-E: Abartılı kalça addüksiyonu. Şekil 3-F: Daire içerisinde gösterilmiş yabancı cisim. Şekil 3-G/H: Uygun olmayan şekilde kısıtlanmış, hatalı ve dar tarama alanı.
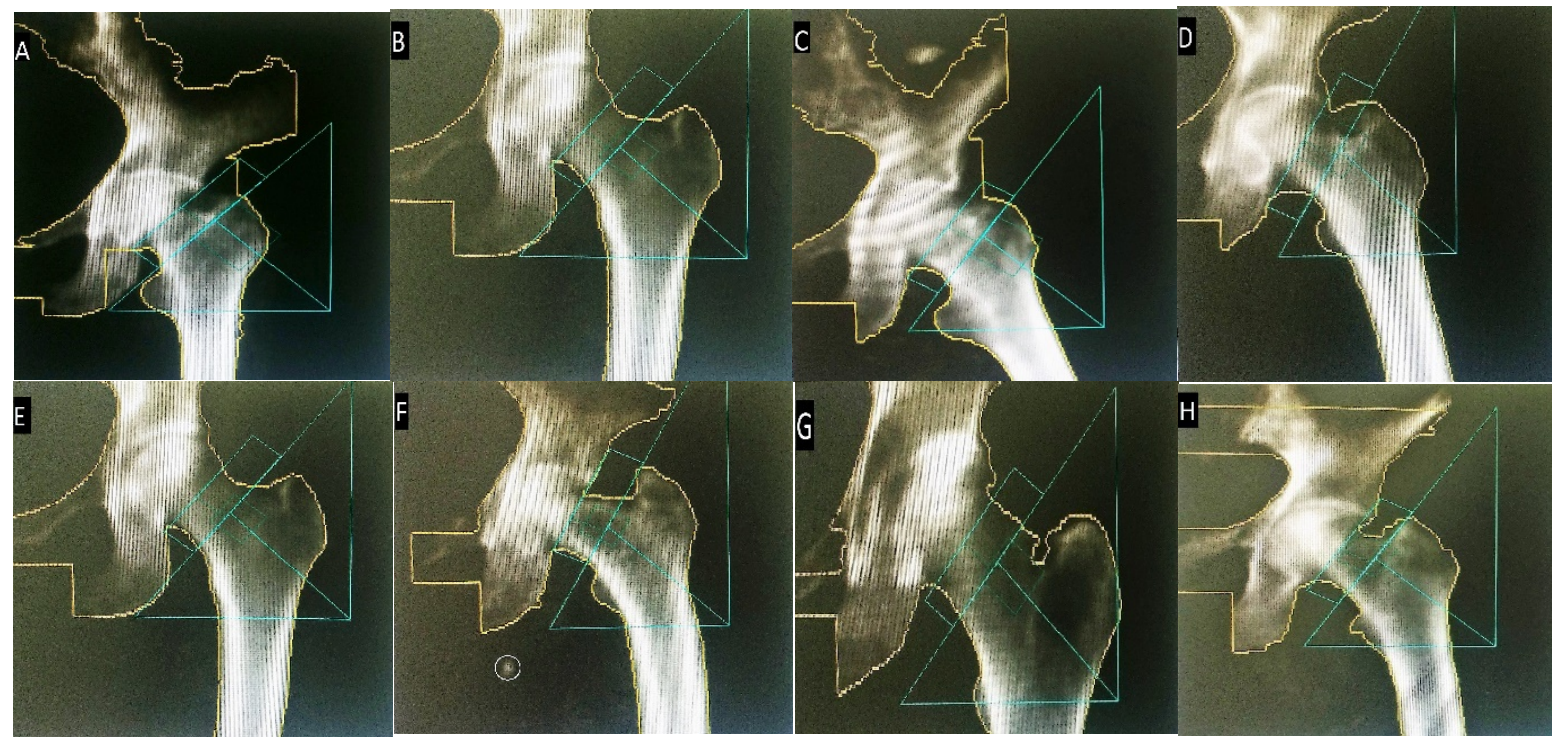

Tablo 3. Proksimal femur DXA ölçümü hataları

\begin{tabular}{|rcc|}
\hline Toplam & $\mathrm{n}=374(\% 49)$ & p değeri \\
Kalça iç rotasyon yetersizliğı & $224(\% 29,3)$ & ${ }^{*} 0,001$ \\
Bölge tanımlama hatası & $64(\% 8,4)$ & 0,060 \\
Yabancı cisim varlığı & $39(\% 5,12)$ & 0,070 \\
Tanımlanan alanın dar olması & $36(\% 4,72)$ & 0,110 \\
Doğuştan kalça çııı̆ı & $11(\% 1,44)$ & 0,317 \\
\hline
\end{tabular}

\section{TARTIŞMA}

Bu çalışmanın sonuçları oldukça yüksek oranda DXA çekim hatalarının hem lomber omurga hem de proksimal kalça çekimlerinde yapıldığını ortaya koymaktadır. DXA lomber omurga, proksimal femur, önkolda ve tüm vücut ölçümlerinde kemik mineral yoğunluğunu etkin bir şekilde 
ölçmektedir(10). DXA ile kemik mineral yoğunluk ölçümü tekrarlanabilir bir biçimde ölçülmekte aynı zamanda bu ölçümler asemptomatik referans toplum ile karşılaştırılmaktadır. Bundan dolayı osteoporozun tanısı için, kırık riskinin tanımlanması ve tedaviye olan yanıtın değerlendirilmesi için DXA oldukça değerli bir yöntemdir (9, $10,11,12,13)$. DXA ile güvenilir ölçüm yapılabilmesi için bazı konularda özen gösterilmesi gerekmektedir. Bu konular ekipman, veri elde etme teknikleri, referans olarak kullanılan veri tabanlarının o topluma uygun olup olmadığı, raporlama yöntemleri ve tanımlayıcı olarak kullanılan terminolojideki farlılıkları içermektedir. DXA çekiminde elde edilen veriler operatörün iskelet sağlığı konusunda bilgisi, bilgisayar programına hastanın demografik verilerinin doğru girilmesi, görüntünün elde edilmesi ve yapılan görüntülemenin incelenmesi becerileri gibi konularda direkt olarak sorumluluğu vardır $(8,11,13)$. Operatör kullandığı bilgisayar ile elindeki çekim alanına ait kemik sınırlarını ve çekim alanı inceleme için uygun biçimde ayarlanmalıdır(11).

Ayrıca kalça kemiği kenarları ve çekim alanı doğru biçimde belirlenmelidir. Özellikle femura ait olan kutunun konumu doğru belirlenmelidir (11). Bundan da anlaşılabileceği gibi DXA çekimi açık olarak operatör bağımlı bir tekniktir. Bu durumda kaliteli bir DXA çekimi için operatörün eğitimli ve deneyimli olması çok önemlidir.

Uluslararası Klinik Dansitometri Derneği tarafından periyodik olarak geliştirme konferansları düzenlenmektedir. Bu konferanslarda sağlık profesyonelleri arasındaki bilgi, beceri ve kaliteyi artırmak, klinisyen ve teknisyenleri eğitmek ve onaylamak, hatalar üzerinde farkındalık oluşturulması, dansitometri erişiminin kolaylaştırılması, klinik ve bilimsel gelişmeleri desteklemek, bilimsel bilgi alışverişini teşvik etmek amacı gerçekleştirilmektedir $(4,14$, 15). Türkiye'de çok fazla DXA çekiminin kalitesinin ve çekim hatalarının ele alındığı çalışma bulunmamakla birlikte daha önce Karahan ve ark. tarafından çok merkezli DXA çekim hatalarını ele alan bir çalışmada DXA çekim hatalarının oldukça yüksek olduğu ve ülkemizde operatör eğitimi standardizasyonunun yeterli olmadığı ortaya konulmuştur (9). Bizim çalışmamız ise tek merkezli olup merkezimizde de benzer sonuçların varlığı aynı şekilde operatör eğitimi standardizasyonun yeterli olmadığını göstermektedir.

DXA çekimi için çalışılacak alanın belirlenmesi oldukça önemlidir. Özellikle Lomber omurgada rotoskolyoz varlığı deneyimli operatörler tarafından dahi hata kaynağı olabilir
$(16,17)$. Tipik bir DXA değerlendirmesinde L2'den L4'e kadar ilerleyen bölgede vertebral alan da kademeli bir artış gözlenmektedir. Ĕger çekimlerde bu alan gözlemlenemiyor ise yanlışlık olması muhtemeldir $(9,16)$. Bizim çalışmamızda da aynı şekilde çalışma alanı seçimi ile ilgili yapılan hatalar omurga çekimleri için en sık karşılaşılan hatalar olarak tespit edildi.

Kendler ve ark. yaptığı bir çalışmada çözünmemiş kalsiyum preparatları DXA çekimlerinde sonuç üzerinde ne kadar etki edeceğini belirlemek amacı ile artefakt olarak kullanılmıştır (14). Bu süperpozisyon sonucunda tek bir omurga kemiğinde \%12,6 yalancı olarak dansite artışı tespit edilmiştir (14). Bu çalışma kalsiyum depozit artefaktlarının aynı şekilde lomber omurga ölçümlerinde belirgin olarak yanlış ölçümlere neden olabileceğini ortaya koymuştur (14). Kalsiyum tableti çalışmasındakine benzer şekilde lomber omurga çekimlerinde, yanlış pozisyonlama ile birlikte normal popülasyonda sıklıkla görülen osteofit oluşumu, aort kalsifikasyonu omurga DXA çekimlerinde hatal sonuçlara neden olabilmektedir (14).

Bizim çalışmamızda DXA çekimlerinde üriner sistem taşı omurga dejeneratif ön tarafında bulunan osteofitlere bağlı gelişen kalsifikasyonlar, non-spesifik olarak omentum kalsifikasyonları mevcuttu. Bu durumlara ek olarak bazı vertebral yapıların yokluğu, spina bifida, laminektomi veya kemikleri normalin dışında skolyoz nedeni ile yerleşim göstermesi tam tersine kemik mineral yoğunluğunda düşüşe neden olabilir(9). Bahsedilen omurga anatomik varyasyonlarının ve postoperatif omurga değişikliklerinin operatör bağımsız çekim sonuçlarını etkilediği aşikar olmak ile birlikte bu durumlarda hastaların klinik, kırık riskini ölçen skalalar (FRAX) ile dikkatlice ele alınması düşünülebilir.

Lomber omurganın osteoporoz ilaçları ile yapılan tedavi (antirezorptif ve anabolizan tedavi) sonucunda oluşan kemik yanıtı kalça bölgesine göre daha yüksektir. Böylesi bir süreç dejeneratif iskelet sorunları varlığında ve omurgaya internal fiksatör uygulandığı durumda gizlenebilmektedir (15). Femur çekimlerinde aynı zamanda doğru pozisyonlama oldukça önemlidir (16). Hastanın femur boynu, çekim yüzeyine paralel olarak seyrettikçe DXA değerleri düşük çıkarken, femur boynunun iç ya da dış rotasyonu ile DXA değerleri kademeli olarak artış gösterir(17). Lekamwasam ve ark. ile Girard ve ark. yaptı̆̆ çalışmada femur rotasyonu iç ya da dış 10 derece ve üzerinde olduğu durumlarda anlamlı ölçüde DXA 
ölçümlerinde değişiklik geliştiğini göstermiştir $(16,17)$. Bizim çalışmamızda femur çekimlerinde en sık karşılaşılan hata pozisyonlama olup hastalarda kalçanın iç rotasyonu en sık karşılaşılan çekim hatası örneğidir. Aşırı adduksiyon ve abduksiyon ile artefaktlar, konjenital kalça dislokasyonu, uygun olmayan çekim diğer hata tipleri idi.

$\mathrm{Bu}$ çalışmanın tek merkezli olması, geniş bir veri tabanı oluşturulamamış olması ve diğer merkezler ile bizim merkezimizde yapılan çekim hatalarının kıyaslayamayışımız çalışmamızın en önemli kısıtıııklarıdır. Bu çalışmada DXA çekiminde çekim hataları özenle taranmıştır. Ancak bu DXA hatalarının klinik olarak ne gibi etkileri olduğu; tedavinin bu hatalardan etkilenip etkilenmediği değerlendirilememektedir.

\section{SONUÇ}

DXA Türkiye'de uzun süredir kullanılmaktadır. Türkiye'de çok fazla DXA çekiminin kalitesinin ve çekim hatalarının ele alındığı çalışma bulunmamakla birlikte daha önce Karahan ve ark. tarafından çok merkezli DXA çekim hatalarını ele alan bir çalışmada DXA çekim hatalarının oldukça yüksek olduğu ve ülkemizde operatör eğitimi standardizasyonun yeterli olmadığı ortaya konmuştur (9). Bizim çalışmamız ise tek merkezli olup merkezimizde de benzer sonuçların varlığı aynı şekilde operatör eğitimi standardizasyonun yeterli olmadığını göstermektedir. Bu nedenle hataların minimize edilmesi için teknisyen/operatör kişilerin uzmanlar tarafından eğitilmesi ve denetlenmesi oldukça büyük önem taşımaktadır. Eğitim almamış ve eğitim almış operatörlerin yaptıkları DXA sonuçlarını karşılaştıran çalışmaların yapılması konuyu daha da aydınlatacaktır. Hatalı çekim sonuçlarının, osteoporoz tedavisi için klinisyenin kararına olası etkilerinin nasıl gerçekleştiğinin anlaşılabilmesi için dair daha ileri çalışmalara intiyaç vardır.

Etik: Bu çalışmanın etik kurulu alınmıştır.

Ethics committee approval had been taken.

Yazar katkı durumu; Çalışmanın konsepti; SB, IU, dizaynı; SB, IU, Literatür taraması; SB, IU, verilerin toplanması ve işlenmesi; SB, IU, istatistik; SB, IU, yazım aşaması; SB, IU,

Author contribution status; The concept of the study; SB, IU, design; SB, IU, literature review; SB, IU, collecting and processing data; SB, IU, statistics; SB, IU, writing phase; SB, iU,

Yazarlar arasında çıkar çatışması yoktur.

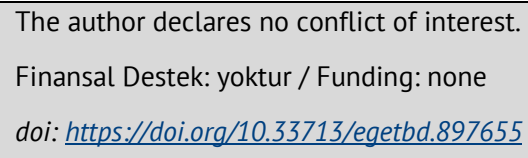

\section{KAYNAKLAR}

1. Ammann P. Lesfacteursdéterminants de la résistancemécaniqueosseuse. Thérapie 2003; 58: 403-7.

2. Manisalı M, Özaksoy D, Doğan S. Osteoporozda radyolojik görüntüleme. Türkiye Klinikleri OrthopaedicsandTraumatology2010; 3: 29-38.

3. Akpolat, VA. Osteoporoz Tanısında Kullanılan Kemik Mineral Yoğunluğu Ölçüm Yöntemleri. Dicle Med J 2008; 35: 216-20.

$\begin{array}{lllr}\text { 4. Guglielmi G, Ferrari F, Bazzocchi A. Bone } & \text { Mineral } \\ \text { DensityandQuantitativelmaging. } & \text { Pitfalls } & \text { in }\end{array}$ DiagnosticRadiologySpringer 2015: 109-32.

5. AllinS, Munce $S$, Carlin L, et al. Fracture risk assessmentafter BMD examination: whosejob is it, anyway? OsteoporosInt2014; 25: $1445-1453$

6. Lewiecki EM, Lane NE. Commonmistakes in theclinicaluse of bone mineral densitytesting. NatClinPractRheum 2008; 4: 66774.

7. Khan AA, Colquhoun A, HanleyDA, et al. Standardsandguidelinesfortechnologistsperformingcentraldualenergy X-ray absorptiometry. J ClinDensitom 2007; 10: 189-95.

8. El Maghraoui A, Roux C. DXA scanning in clinicalpractice. QJM 2008; 101: 605-17.

9. Karahan AY, Kaya B, Kuran B, et al. Commonmistakes in thedual-energy $x$-ray absorptiometry (DXA) in Turkey. A retrospectivedescriptivemulticenterstudy. ActaMedica2016; 59: 117-23.

10. Bonnick, SL, JohnstonJr CC, Kleerekoper M, et al. Importance of precision in bone densitymeasurements. J ClinDensitom 2001; 4: 105-10.

11. Vasić J, Gojković F, Zvekić-Svorcan J, et al. Themostcommonmistakes in bone mineral densitytestingwith DXA method. MD-Medicaldata 2013; 5: 271-8.

12. Sindel D, Gula G. Assessment of Bone Mineral Density in Osteoporosis.Turk J Osteoporos 2015; 21: 23-9.

13. Guglielmi G, Diano D, Ponti F, et al.QualityAssurance in Bone Densitometry. CurrRadiolRep 2014; 2:33.

14. Kendler DL, Kiebzak GM, Ambrose CG, et al. Effect of calciumtablets on interpretation of lumbarspine DXA scans. J ClinDensitom 2006; 9: 97-104.

15. Wong JC, Ong B. Evaluation of femurangleabduction/adductionand bone mineral densityvalues. J ClinDensitom 2005; 8: 472-5.

16. Lekamwasam $S$, Sumith $R$, Lenora J. Effect of legrotation on hip bone mineral densitymeasurements. J ClinDensitom 2003; 6: 331-6.

17. Girard MS, Sartoris DJ, Moscona AA, et al. Measuredfemoraldensitybydual-energy X-ray absorptiometry as a function of rotation. Orthopaedicreview 1994; 23: 38-40. 